\title{
Survey of satisfaction with care in a rheumatology outpatient clinic
}

\author{
J Hill, H A Bird, R Hopkins, C Lawton, V Wright
}

\begin{abstract}
Consumer satisfaction is increasingly recognised by hospital administrators and health care providers as an important aspect of health care. A study was undertaken to investigate the satisfaction with care among patients with rheumatoid arthritis (RA) attending a rheumatology outpatient clinic at Leeds General Infirmary. The Leeds satisfaction questionnaire was developed and rigorously tested for reliability (Cronbachs alpha) and stability (test/retest). The Leeds satisfaction questionnaire was then completed by 70 patients with RA who had attended the Leeds General Infirmary on at least three previous occasions.

The results showed that patients were, in general, satisfied with the care they received. The highest satisfaction scores were obtained on the scale for technical quality and competence of health professionals. The least satisfaction was accredited to the difficulty of unscheduled access to the clinic and the lack of continuity with the providers of care. The time spent in the waiting area before consultation was highlighted as the one aspect which caused the greatest dissatisfaction.
\end{abstract}

Although satisfaction is a desirable outcome in its own right, it can also influence whether a person seeks medical advice, complies with treatment, and maintains a continuing relationship with a practitioner. ${ }^{12}$ This is particularly important for patients with rheumatoid arthritis (RA), whose illness lasts a lifetime.

Primary care,,$^{3-7}$ inpatient care,,$^{8-13}$ and outpatient services ${ }^{14-19}$ have been the subject of satisfaction studies. Previous papers confirm that most patients are satisfied with their encounters with health care. Dissatisfaction is usually related to communication, empathy, time and accessibility, and the attitudes of health care professionals towards their clients. As no suitable measuring instrument was available, the Leeds satisfaction questionnaire was developed in this work.

\section{Patients and methods}

DEVELOPMENT OF THE LEEDS SATISFACTION QUESTIONNAIRE

Satisfaction is an attitude ${ }^{20}$ and the appropriate measurement tool is that of attitude scales. The respondent is asked to agree or disagree with a number of statements using five-point Likert type scales. ${ }^{21}$ The responses chosen for the Leeds satisfaction questionnaire were: strongly agree, agree, not sure, disagree, and strongly disagree. The Leeds satisfaction questionnaire contains items on five subject groups chosen from the taxonomy derived by Ware et $a l^{22}$ : provision of information; empathy with the patient; attitude to the patient; access to and continuity with the care giver; and technical competence. A sixth group of items relating to overall satisfaction was added for validation purposes.

The first draft of the Leeds satisfaction questionnaire consisted of an item pool of 58 statements based on previously validated satisfaction questionnaires. ${ }^{4223}$ They were evenly balanced between favourable and unfavourable statements to avoid an acquiescent response bias $^{24}$ and were placed in a random order. The most positive attitude gave the highest score.

The Leeds satisfaction questionnaire was tested in a pilot study of patients attending two consecutive rheumatology outpatient clinics at the Leeds General Infirmary $(n=29)$. All patients were aged between 33 and 77 years (mean 52 years, median 53 years), had a diagnosis of rheumatoid arthritis (RA) and had visited the rheumatology outpatient clinic on at least three previous occasions. Only three patients were men.

After completing the questionnaire, a researcher $(\mathrm{JH})$ ascertained their views on its comprehensibility, length, and ease of completion. No difficulties were noted with respect to understanding and only two patients left statements unanswered.

The standard deviation of scores for each of the 58 items ranged from 0.45 to $1 \cdot 30$, with mean scores from 3.03 to 4.41 , reflecting the positive skew. Internal consistency was tested using Cronbach's alpha $(\alpha){ }^{25}$ The total scale was $\alpha=0.97$; results from the subscales are shown in the table. The association between the scales was tested by correlating each subscale with the total score for that group using Pearson's $r$ value (table). The results showed the Leeds satisfaction questionnaire to be reliable.

Items were then screened for inclusion in the

Reliability and consistent coefficients of the Leeds satisfaction questionnaire (LSQ)

\begin{tabular}{llll}
\hline Subscales & \multicolumn{2}{l}{$\begin{array}{l}\text { Chronbachs Pearson } \\
\alpha^{*}\end{array}$} & $\begin{array}{l}\text { Pearson } \\
\text { r }\end{array}$ \\
\hline Overall satisfaction & 0.81 & 0.79 & 0.95 \\
Information & 0.93 & 0.97 & 0.94 \\
Empathy & 0.87 & 0.97 & 0.92 \\
Technical competence & 0.88 & 0.91 & 0.91 \\
Attitude & 0.71 & 0.92 & 0.79 \\
Access and continuity & 0.84 & 0.84 & 0.98 \\
\hline
\end{tabular}

"Internal consistency (Cronbachs $\alpha$ ) (original LSQ).

tCorrelation of total scores with subscales (Pearson $r$ ) †Correlation of total scores with subscales (Pearson $r$ ) (revised LSQ). 
Leeds satisfaction questionnaire using the response range, mean score and standard deviation. Thirteen statements with low variability were excluded (standard deviation $=0 \cdot 7$ or less) and two were changed from positive to negative to restore the balance.

The revised Leeds satisfaction questionnaire was tested again using 16 women and four men whose ages ranged from 38 to 71 years (mean and median 55 years). Two patients failed to complete entire pages and these questionnaires were not analysed.

The standard deviation for individual items ranged from 0.5 to 1.2 and the mean score from 2.67 to 4.39 , showing the questionnaire to be less biased. The reliability tests were repeated. Cronbach's $\alpha$ for the total scale was 0.96 and correlations of the total scores with the scores from each subscale remained satisfactory (table).

Stability was tested by test/re-test on 14 patients who had supplied their home address. Questionnaires were posted to these patients one month after they had first completed it. The total scale score was correlated with their original score using Pearson's $\mathbf{r}(0.83)$. It was concluded that the Leeds satisfaction questionnaire is reliable and stable.

\section{INVESTIGATION OF PATIENT SATISFACTION}

To assess patient satisfaction, the Leeds satisfaction questionnaire was completed by 70 randomly selected patients with RA who had attended the rheumatology outpatient clinic on at least three previous occasions. As the Leeds satisfaction questionnaire contains a different number of items in each subject group, scores were normalised in the range one to five to facilitate comparison between groups. Higher scores indicate a positive response, with a score of three indicating no feelings either way.

\section{Results}

The patients were aged 22-75 years (mean and median 56 years); the duration of disease was from 1 to 40 years and 52 of 70 patients were women. The figure shows the mean scores and range from each subgroup.

\section{INFORMATION}

The overall score for this component was 3.39 . Although $30(43 \%)$ patients did not feel that they were encouraged to ask questions, $73 \%$ thought that when they did ask they were

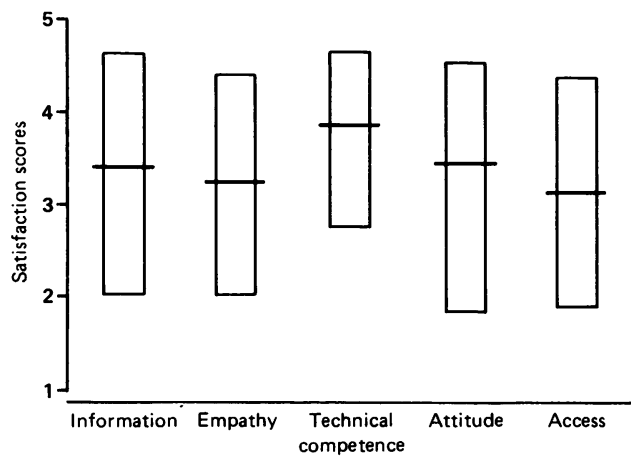

Figure Range of scores in each subgroup. The bar indicates the mean value. answered in words which they could understand. A similar number $(73 \%)$ felt that they were given a clear explanation of why they had radiography and blood tests. Most thought that they were given an adequate explanation for their treatment with drugs. However, in response to the statement 'Side effects of tablets are rarely discussed', three patients strongly agreed, 23 agreed and seven were not sure, leaving just over half $(53 \%)$ of the cohort satisfied.

\section{EMPATHY}

The empathy scale was weakly biased towards satisfaction. ${ }^{3}{ }^{23}$ Sixty six per cent of patients did not find their visit to the rheumatology outpatient clinic stressful and the same number felt able to talk about their concerns during consultation. Just over half (58\%) thought that the person they saw in the clinic knew what it was like to have arthritis. Sixty four per cent considered that their feelings about their treatment were taken into consideration, but the score of $2 \cdot 88$ to the question 'I'm rarely asked which treatments I would prefer' shows some discontent. Only $34 \%$ agreed that they were consulted regarding treatment preferences. Fewer than one patient in four $(23 \%)$ agreed that the person they saw in the clinic took an interest in their family $(2.74)$ and only one in three $(33 \%)$ felt that interest was shown in the way that arthritis affected family relationships (3.08).

\section{TECHNICAL QUALITY AND COMPETENCE}

In common with many satisfaction studies, the patients were found to be most satisfied with the technical quality of their care, the overall score of 3.84 being the highest of any of the component groups. A typical result was evoked by the statement 'I feel I'm in good hands when I come to the clinic'; 56 agreed, 11 strongly agreed and the remaining three were not sure.

\section{ATTITUDE TO THE PATIENTS}

The overall score for this group was $3 \cdot 44$, but there were some areas of dissatisfaction. Most patients were satisfied that they were treated as people rather than as a disease. Seventy nine per cent felt that their consultation was of adequate length and the same percentage agreed that they were listened to. The mean score for the statement 'I'm usually kept waiting a long time in the waiting area' was $2 \cdot 5$, the highest level of dissatisfaction found, with 44 (63\%) patients dissatisfied and five 'not sure'. Despite being kept waiting, $49(70 \%)$ agreed with the statement 'No matter how long you have to wait in the clinic, it's worth it'.

\section{ACCESS AND CONTINUITY}

This subgroup was judged the least satisfactory with an overall group score of $3 \cdot 12$.

Fewer than half the patients $(49 \%)$ saw the same person at each clinic visit, leaving the patients dissatisfied (2.93). Although 47\% agreed that they were encouraged to contact the clinic if they had a problem, many patients $(64 \%)$ were unsure as to whether they could obtain advice by telephone and only $40 \%$ 
thought that they would be able to get in touch with someone if a problem arose. Nineteen respondents $(27 \%)$ believed that they could get an urgent appointment if it was needed, but $56 \%$ were unsure on this point.

OVERALL SATISFACTION

This group of items was for validation purposes. The score of 3.44 compares well with the overall mean score from the other groups. Eighty six per cent of patients were either satisfied $(77 \%)$ or highly satisfied $(9 \%)$ with the care they received in the clinic. However, $10 \%$ were not sure and three (4\%) were dissatisfied. There was less agreement with the statement 'There are some things about my care in clinic which could be improved'; $43 \%$ were uncertain, $20 \%$ agreed with the statement and $36 \%$ disagreed.

\section{Discussion}

Many factors contribute to the high levels of satisfaction found in surveys, including social desirability, ${ }^{26}{ }^{27}$ reluctance to express negative opinions, ${ }^{28}$ item wording, ${ }^{29}$ and location of testing. ${ }^{27}$

Patients showed most satisfaction with technical quality and competence. A possible explanation is that dependent patients feel uncomfortable with the idea that their care may be less than adequate. ${ }^{30}$ Doubts have been expressed regarding the competence of patients to judge the technical quality of care, but as there is no evidence by which to judge their abilities, and as patients are the 'consumers', it was considered appropriate for inclusion.

The lack of interest shown in the patient's family caused some dissatisfaction. Rheumatoid arthritis not only affects the patient, but alters the lives of those closest to them. Those with severe disease may become increasingly dependent on their spouse or children and their role within the family frequently changes. It is important to treat the patient within this context.

Access and continuity was the area of least satisfaction, confirming the findings of other workers. ${ }^{4}$ Continuity of care is often difficult to achieve as health carers, particularly medical staff, are required to rotate as part of their training. Even so, with forethought most patients could be seen by the same professional on each clinic visit. The problem of contacting the clinic for advice could be eased by the installation of a 'help line' manned for specific periods of time. This would give patients access to a knowledgeable source at minimum cost and with little inconvenience.

The one item which caused the greatest dissatisfaction was time spent in the waiting area. In general, patients are very tolerant and as Durrani et $a l^{18}$ have stated 'They [patients] expect, and are reasonably tolerant with, delays in seeing their doctor. However they object to not being told the reasons for delay and the approximate time they therefore should add to their actual appointment time'. It may be possible to reduce the waiting time by streamlining appointments, but when delays are inevitable patients should be given an explanation for the delay and an estimate of their appointment time.

The results from this study suggest that patients with RA are reasonably satisfied with their outpatient care, but, as may be expected in a busy clinic, there is scope for improvement.

Pope $^{29}$ has said 'Satisfaction and dissatisfaction are not mutually exclusive but are likely to live side by side. It is not only possible but highly likely that a person may be generally satisfied with something but still have a number of dissatisfactions with it'

Questionnaires such as the Leeds satisfaction questionnaire are useful tools with which to assess satisfaction, highlight problems, and ultimately assess solutions.

1 Korsch B, Gozzi E, Francis V. Gaps in doctor-patient corsch B, Gozzi E, Francis V. Gaps in doctor-patien communication-1. Doctor-patient

2 Larsen D E, Rootman I. Physician role performance and patient satisfaction. Soc Sci Med 1976; 10: 29-32.

3 Cartwright A. Patients and their doctors. London: Routledge and Kegan Paul, 1967.

4 Hulka B S, Zyzanski S J, Cassel J C, Thompson S J. Scale for the measurement of attitudes towards physicians and primary medical care. Med Care 1970; 8: 429-36.

5 Kincey J, Bradshaw P, Ley P. Patients' satisfaction and reported acceptance of advice in general practice. $\mathcal{F} R \mathrm{Col}$ Gen Pract [Occas Pap] 1975; 25: 558-66.

6 Mangen S P, Griffith J. Patient satisfaction with community psychiatric nursing: a prospective controlled study. $\mathcal{F} A d v$ Nurs 1982; 7: 477-82.

7 Hull F M, Hull F S. Time and the general practitioner: the patient's view. $\mathcal{F} R$ Coll Gen Pract [Occas Pap] 1984; 34 patien $71-5$.

8 McGhee A. The patients' attitude to nursing care. Edinburgh: E S Livingstone, 1961

9 Cartwright A. Human relationships and hospital care. London: Routledge and Kegan Paul, 1964.

10 Raphael W. Do we know what patients think? A survey comparing the views of patients, staff and committee members. Int $\mathcal{F}$ Nurs Stud 1967; 4: 209-23.

11 Raphael W. Patients and their hospitals: a survey of patients' views of life in general hospitals. London: King Edward's Hospital Fund for London, 1969.

12 Hurst K. A question of satisfaction. Nursing Mirror 1985; 161: $51-6$.

13 Moores V, Thompson A G H. What 1357 hospital inpatients think about aspects of their stay in British acute hospitals. think about aspects of their stay

14 Royal Commission on the National Health Service. London: HMSO, 1979.

15 Francis V, Korsch B M, Morris M J. Gaps in doctor-patient communication. Patients response to medical advice. N Engl F Med 1969; 280: 535-9.

16 Linn L S. Factors associated with patient evaluation of health care. $M M F Q$ 1975; 53: 531-48.

17 Porter M, Macintyre S. What is, must be best: a research note on conservative or deferential responses to antenatal care on conservative or deferential responses to
provision. Soc Sci Med 1984; 19: 1197-200.

provision. Soc Sci Med 1984; 19: 1197-200.
18 Durrani J, Hague K, Hurst K. Patient satisfaction in outpatients. Nursing Times 1988; 84: 47.

19 Sensky T, Dennehy M, Gilbert A, et al. Physicians' perceptions of anxiety and depression amongst their outpatients: relationships with patients and doctors' satisfaction with their interviews. F $R$ Coll Physicians Lond 1989; 23: 33-8.

20 Oppenheim A N. Questionnaire design and attitude measurement. England: Gower, 1986.

21 Likert R. A technique for the measurement of attitudes. Arch Psychol (Franke) 1932; 140: 1-55.

22 Ware J E, Snyder M K, Wright W R, Davies A R. Defining and measuring patient satisfaction with medical care. Evaluation and Program Planning 1983; 6: 247-63.

23 Risser N L. Development of an instrument to measure patient satisfaction with nurses and nursing care. Nurs Res 1975; 24: 45-52.

24 Ware J E. Effects of acquiescent response set on patient satisfaction ratings. Med Care 1978; XVI: 327-36.

25 Cronbach L J. Coeficient alpha and the internal structure of tests. Psychometrika 1951; 16: 297-34.

26 Lebow J L. Consumer assessments of the quality of medical care. Med Care 1974; 12: 328-37.

27 French K. Methodological considerations in hospital patient opinion surveys. Int $\mathcal{f}$ Nurs Stud 1981; 18: 7-32

28 Hulka B S, Zyzanski S J, Cassel J C, Thompson S J. Satisfaction with medical care in a low income population. f Chronic Dis 1971; 24: 661-73.

29 Pope C R. Consumer satisfaction in a health maintenance organisation. F Health Soc Behav 1978; 19: 291-303.

30 Tessler R, Mechanic D. Consumer satisfaction with prepaid group practice: a comparative study. $\mathcal{F}$ Health Soc Behav 1975; 16: 95-113. 